\title{
Success from failure: US federal commercial tobacco regulation
}

\author{
Desmond Jenson
}

Public Health Law Center, Saint Paul, Minnesota, USA

\section{Correspondence to Desmond Jenson, Public Health Law Center, Saint Paul, MN 55105, USA: \\ desmond.jenson@ mitchellhamline.edu}

Received 26 July 2021 Accepted 9 November 2021

\section{ABSTRACT}

The history of the US Food and Drug Administration's (FDA) regulation of tobacco products is fraught with failures. A first effort to regulate tobacco products was completely dismantled. Despite robust authority to act, the current iteration of the FDA has also struggled to succeed. While the public health community may be frustrated by the lack of progress to date, recent developments have potentially shown advocates a pathway for success.

Thirty years is a long time. It is a literal lifetime for the journal, Tobacco Control. It is roughly the length of time that we consider to be one generation of the human lifespan. That means that when Tobacco Control was publishing its first issue, some of the researchers that now publish were children or not yet born. In the 30 years that Tobacco Control has been publishing cutting-edge research, the legal landscape of tobacco control in the USA has also gone through a generational change.

Thirty years ago, there was essentially no oversight over tobacco products. Cigarettes were taxed consistently, other products less so. There were warning labels on the sides of cigarette packages to inform people of what the Surgeon General had been professing for decades. ${ }^{1}$ There was clear science that secondhand smoke was harmful and communities were beginning to restrict smoking. ${ }^{2}$ That seems like a pittance of regulation for a deadly product, and by today's standards, it is, but even that modicum of control was hard fought for decades. Importantly, most policy change was happening at the state and local level, piecemeal, rather than comprehensively at the federal level.

The idea of federal oversight was not new but the lobbying power of the tobacco industry had kept any real threat of federal regulation at bay. Without comprehensive federal oversight, advocates were forced to fight the same battle, community by community, over and over again, winning some and losing others. It is now known that this scattered approach to regulation can create and has exacerbated health disparities. So, while advocates felt as though the war against Big Tobacco was being won, a dynamic was created that remains entrenched today, contributing to the flood of policies that disproportionately hurt some communities, even as they benefit others. Most of the blame for health disparities in tobacco-caused disease can be laid at the feet of cigarette manufacturers, who have routinely targeted specific communities for decades, but our piecemeal policymaking is certainly a contributing factor. ${ }^{3}$
The lack of comprehensive, federal oversight has also meant that cigarette manufacturers were free to tweak ingredients and constituents and introduce new products whenever and wherever they pleased. Other than a prohibition on television and radio advertising, manufacturers were also free to advertise as they saw fit. Billboards, sports stadium advertisements and cigarette merchandise were commonplace. The younger generations cannot possibly fathom how ubiquitous the cigarette used to be in American culture.

The tides began to turn in the mid-1990s when whistleblowers brought documents and personal accounts of what was happening behind closed doors in cigarette factories and Big Tobacco's boardrooms. Media outlets flooded newspapers and television with damning accounts of cigarette manufacturers 'spiking' cigarettes with additional nicotine and using other chemical additives to increase the addictiveness of their products. ${ }^{4}$ Documents revealed that the tobacco industry knew just how harmful their products were and the lengths that they would go to in order to keep that information secret.

Finally, the public outcry captured the attention of people who had the power to do something about it. Several states' attorneys general filed lawsuits against cigarette manufacturers. ${ }^{5}$ These efforts ultimately led to settlement agreements, including the Master Settlement Agreement, one of the largest civil settlements in the history of the US judicial system. ${ }^{6}$ Eventually, the federal government also filed a racketeering lawsuit against the same companies, a lawsuit that is still actively being litigated more than 20 years later.

Of possibly equal importance to those actions is a concurrent policy failure: the attempt by the US Food and Drug Administration (FDA) to regulate cigarettes as drug delivery devices. The idea was novel: nicotine meets the federal definition of a drug because it affects structures and functions of the human body and, because people smoke cigarettes for the nicotine, cigarettes are a device that delivers a drug. Because the FDA has the authority to regulate drugs and drug delivery devices, why not regulate cigarettes? In 1996, under then-Commissioner David Kessler, the FDA moved forward with an attempt to create a comprehensive, coast-to-coast regulatory scheme for the world's most dangerous consumer product, at a time when not every state was enforcing a minimum legal sales age. ${ }^{7}$ Ultimately, cigarette manufacturers escaped the grasp of regulators by convincing the courts that the FDA's authority over drugs could not extend to cigarettes. Big Tobacco's argument was that when it comes to drugs, the FDA uses a standard based on 
safety and efficacy and because cigarettes are so dangerous, the FDA would have no choice but to ban the product, a move that they argued could not have been the intention when Congress gave the FDA the authority to regulate drugs. Even though the FDA had no intention of completely banning cigarettes, the US Supreme Court agreed with the cigarette companies and struck down the FDA's action.

Although it was eventually dismantled, David Kessler's team at the FDA, which included current director of the FDA's Center for Tobacco Products, Mitch Zeller, deserves credit for moving forward with a bold idea. The team built a regulatory infrastructure that the current iteration of the FDA still uses to regulate tobacco products. Perhaps most importantly, they should be credited with forcing the public and government officials to get used to the idea of comprehensive regulation of cigarettes at the federal level. Given the behaviour of cigarette companies and the public backlash that led to successful government lawsuits, it probably seemed to many that oversight was an inevitability, one that even the tobacco industry's lobbying machine could not overcome. Even so, it was a daring move by a US regulatory agency, one that is often overlooked because the effort ultimately failed, but one that deserves significant credit for starting a chain of events that will likely save many lives.

If you know how this story ends, you also know that between 2000, when the Supreme Court struck down the Kessler-led FDA's action, and 2009, when President Barack Obama took office, many attempts were made to pass legislation that would specifically allow the FDA to regulate tobacco products but no bill ever made it to the president's desk. The 2008 election brought in a Democratic president and increased Democratic majorities in both houses of the US Congress. The time had finally come to make the Family Smoking Prevention and Tobacco Control Act (TCA or the Act) law. The date 22 June 2009 was a historic day in the history of tobacco control in the USA as it marks the beginning of the FDA's regulation of tobacco products and the creation of the FDA's Center for Tobacco Products. And yet, the expected sea change that was to follow, never manifested.

Failure is a strong word and one that other journals have not liked to print. However, the FDA's first attempts at regulating cigarettes with the appropriate legal authority ultimately failed. ${ }^{8-11}$ The first major test was the development of graphic health warning labels for cigarette packages and advertisements. In passing the TCA, Congress specifically required the FDA to develop such warnings and specified the date that the warnings must become law. While the agency ultimately developed the warnings and published the final version of its regulation on the Congressional deadline, unsurprisingly, the cigarette manufacturers filed a winning lawsuit and the warnings never appeared on packages or advertisements.

Any lawyer will tell you that litigation carries significant risk. The judicial system was not designed for the evaluation of the comparative scientific merit of competing ideas. The courts hearing the challenge to the FDA's rule were mired in the false idea that there is a dichotomy between emotion and fact and that FDA's warnings were meant to illicit emotion and thus not fact based. ${ }^{12}$ The courts decided that forcing commercial entities to carry an emotional government message was an infringement of protected speech rights. The policy died a slow death in the courts.

Importantly, even though the FDA had finalised a rule that was struck down, the language of the TCA does not require the FDA to try, it requires the agency to succeed. After failure in the courts, the FDA had stated its intention to start a new rule. However, after 4 years, it was no longer clear whether the FDA was entirely committed to the goal, or at least, accomplishing it in a timely manner. A coalition of public health groups took a brave step and filed a lawsuit against the FDA for failing to promulgate a new rule establishing graphic warnings.

It is critical to put this action into context. For decades, tobacco product manufacturers, in particular, cigarette manufacturers, have used litigation as a tool to forestall progress, often filing frivolous suits or threatening lawsuits on bogus grounds to scare state and local governments from taking actions to protect their own citizens. In the world of tobacco control, the idea of litigation against the government as a legitimate policy lever for positive change was a foreign concept. It had been a generation since the good guys had sued the bad guys. A lawsuit against the government also creates a dynamic where public interest advocates and public health regulators are in opposition to each other. Those of us who work for non-profit public health organisations like to think of ourselves as largely on the same side as the government, with the industry in opposition. The judicial system in the USA is adversarial which means that to use litigation as a tool, one must oppose another party. In the context of FDA regulation, the only entity to sue is the government and that forces those in public interest to put themselves on the opposite side from the government organisations that had historically been collaborators.

The risk paid off and the public health groups succeeded in persuading a court to force the FDA to start and finish a new process to establish graphic warning labels. This first lawsuit has potentially opened a floodgate as two additional lawsuits have been filed by public health groups against the FDA. In a second suit, public health groups were able to force the FDA to actually implement premarket review for products that came under the agency's authority in 2016. The FDA had intended to delay review to as late as 2022 . The most recent lawsuit is worth discussing in greater detail.

The right to petition the government is articulated in the First Amendment to the US Constitution. It is probably the least discussed provision in that amendment. As with other rights, the right to petition has evolved over time. One current manifestation is the Citizen Petition. Every federal executive branch agency is required to adopt procedures to allow any interested person to make a request of that agency. Not only that but current law also requires that agency to meaningfully consider the request and respond to the petitioner.

Over the past 12 years, the FDA has only received a handful of petitions specific to tobacco products. A 2013 petition filed by over a dozen groups requested that the FDA finally remove menthol from cigarettes. Even though the agency had recognised the devastating health consequences caused by menthol cigarettes and professed a desire to act, a proposed rule to prohibit menthol had never seen the light of day. Despite the legal requirement to respond, the FDA never approved or denied the request and so some of the petitioners filed a lawsuit compelling the FDA to act.

The lawsuit was filed by the African American Tobacco Control Leadership Council and Action on Smoking and Health on 17 June 2020. In order to dispense with claims related to the petition, the FDA committed to acting on the petition and on 29 April 2021, the agency sent a letter to the petitioners stating that the petition had been granted. One could dwell on the 8 years that the petition sat unanswered at the FDA, but instead, there might be a lesson in the fact that less than 1 year elapsed between the filing of the lawsuit and the agency finally doing the right thing. Obviously, menthol cigarettes are still on the market, and it is likely that it will be several years before the FDA actually enforces a prohibition. However, the agency has taken a step that cannot be undone. The petition and the litigation have 
finally set our nation on a one-way path toward the likely end of menthol cigarettes.

Even though the Citizen Petition was granted, the government continues to defend its position in court that the FDA can now proceed with a rulemaking without any specific deadlines. Plaintiffs continue to push the court to impose deadlines on the FDA. However, the grant of the petition is an important step because it would be difficult if not impossible for the FDA to undo. The grant or denial of a petition can be reviewed by a court. In doing so, that court must decide whether the grant or denial is arbitrary and capricious. The FDA would find it difficult to demonstrate that a decision contrary to the scientific evidence passed this test. In the case of menthol, the FDA deciding to reverse course and deny a petition would challenge the agency to overcome all of the evidence compiled by petitioners, plaintiffs and the FDA itself. A court would also look at past supportive statements by FDA staff. The one benefit to the years of FDA delay is that agency has formally committed to action and it cannot go back. In addition, because the petition was granted, continued delay to implement that grant would also eventually create a cause of action that could provide a court with a reason to impose deadlines on the FDA. Even if a court does not impose a deadline on the FDA now, if the FDA fails to finalise or propose a rule when it has represented that it will, a court can still impose a new deadline.

While we cannot yet celebrate the removal of menthol cigarettes from the marketplace, public health advocates can celebrate the discovery of a tool with tremendous potential to benefit public health. One can envision a process where any particular policy with a strong evidence base can be petitioned for and after a period of inaction, the petitioner can sue the agency for failure to act on the petition. When forced to decide, if the evidence base shows that the policy would protect public health, it is exceptionally difficult for the FDA to deny the petition, lest the plaintiffs argue that the action is arbitrary and capricious. A likely outcome is that the agency acts as it did with menthol, granting the petition and starting the rulemaking process, a slow process but one that ends with policy change. For particularly impactful policies, it is possible that courts would force the FDA to act quickly.

This may not work on every occasion but consider the difference in time and resources of filing a petition and suing the FDA versus decades of lobbying the US Congress and waiting for the political stars to align in order to make incremental change. Perhaps the TCA did bring about a sea change and it just took us several years to find the right tools to make that change happen.

Equipped with this knowledge, what happens next? Collaboration will be essential to moving policy forward in the future. The menthol petition required months of cooperation between some of the most respected scientific and legal minds in tobacco control, completely fixated on sorting out all of the nuanced scientific and legal details. This was a topic with an already robust evidence base. Most importantly, the work was led by Black advocates who had been focused on removing menthol cigarettes long before the FDA could act.

As advocates move forward, the highest and best use of our new tools is to focus on health equity with laser-like precision. In every action that the FDA takes, it must assess policy outcomes through the public health standard, a three-prong, populationlevel decision-making matrix that includes initiation, cessation, and the impact on both users and non-users of tobacco products. The FDA must use this standard in virtually every affirmative action that the agency takes and yet, after 11 years, the FDA has yet to unpack the statutory language and provide itself a rubric for how to use the standard to weigh the evidence. While disappointing, that does mean that the public health community still has ample opportunity to ensure that this standard is centred in health equity.

Before advocates begin flooding the FDA with Citizen Petition litigation, careful consideration must be given to all of the various policies that the FDA could enact and their potential outcomes. In order to centre that work in health equity, those policy ideas must come from groups that are part of the communities that have been the subject of tobacco industry targeting. The first successes on menthol were possible because of Black leaders and their allies working together. That success can be duplicated but only in a careful and coordinated fashion. Advocates who have been active in FDA regulation must begin to coordinate more closely with community-based organisations and groups that represent industry-targeted communities. Only when national and local advocates are collaborating with researchers and lawyers can all of the pieces fall into place.

It is incumbent on all people and organisations in tobacco control to communicate effectively to ensure that the public health community's priorities for FDA regulation are being pursued jointly. While David Kessler's FDA built an organisation that was dismantled, advocates have been able to take that blueprint and build something new. Tobacco control advocates have been given a new blueprint with the menthol citizen petition and lawsuit. With it, perhaps the public health community will begin to take more significant steps forward at the federal level.

What this paper adds

While most tobacco control advocates are generally aware of the FDA's regulation of tobacco products, few understand the connection between today's FDA and the attempts by the agency to regulate the products some 25 years ago.

- Even though the FDA has made little progress in its regulation of tobacco products, advocates have been able to use litigation to shape the future of tobacco control.

- Few people are aware of the power of the Citizen Petition to not just put an idea before the FDA, but to force the agency to consider the idea and potentially take action. Used carefully, this tool may prove instrumental in future regulatory progress, particularly on issues that advance health equity.

\section{Twitter Desmond Jenson @desmondjenson}

Acknowledgements The author would like to thank the Robert Wood Johnson Foundation for its continued support of the Public Health Law Center's efforts to push for strong federal regulation of commercial tobacco products.

Contributors DJ conceived and wrote this article.

Funding This work was supported by the Robert Wood Johnson Foundation.

Competing interests None declared.

Patient consent for publication Not required.

Ethics approval This study does not involve human participants.

Provenance and peer review Commissioned; externally peer reviewed.

ORCID iD

Desmond Jenson http://orcid.org/0000-0002-7251-1737

\section{REFERENCES}

1 Public Law 89-92, §2, July 27, 1965, 79 Stat. 282.

2 Institute of Medicine. Secondhand smoke exposure and cardiovascular effects: making sense of the evidence. Washington DC: National Academies Press, 2010. https://www. ncbi.nlm.nih.gov/books/NBK219565/ 
3 Yerger VB, Przewoznik J, Malone RE. Racialized geography, corporate activity, and health disparities: tobacco industry targeting of inner cities. J Health Care Poor Underserved 2007;18:10-38.

4 Weiser B. ABC and tobacco: the anatomy of a network news mistake, 1996. Washington post. Available: https://www.washingtonpost.com/archive/politics/1996/ 01/07/abc-and-tobacco-the-anatomy-of-a-network-news-mistake/9d9a0418-e81f4565-ad22-8e78f192fc2b/

5 Schwartz J, Torry S. Tobacco firms, Mississippi SETTLE, 1997. Washington Post. Available: https://www.washingtonpost.com/archive/politics/1997/07/04/tobaccofirms-mississippi-settle/08edc646-4305-4b03-b82d-cdadc6ad8584/

6 National Association of Attorneys General. The tobacco master settlement agreement. Washington DC: National Association of Attorneys General. https://www.naag. org/our-work/naag-center-for-tobacco-and-public-health/the-master-settlementagreement/
7 Kessler DA, Witt AM, Barnett PS, et al. The food and drug administration's regulation of tobacco products. N Engl J Med 1996;335:988-94.

8 Jenson D, Lester J, Berman ML. FDA's misplaced priorities: premarket review under the family smoking prevention and tobacco control act. Tob Control 2016;25:246-53.

9 Jenson D. Ten years of FDA tobacco regulation: lessons for public health stakeholders. J Leg Med 2020;40:335-53.

10 Hemmerich N, Jenson D, Bowery BL. Underutilisation of no-tobacco-sale orders against retailers that repeatedly sell to minors, 2015-2019. Tobacco Control (Published Online First: 08 June 2021).

11 Berman $M$, Jenson $D$. The food and drug administration as gatekeeper and the menthol exemption. Am J Pub Health 2021;111:E6.

12 Popova L, Owusu D, Jenson D, et al. Factual text and emotional pictures: overcoming a false dichotomy of cigarette warning labels. Tob Control 2018;27:250-3. 